\title{
Surface display of glycosylated Tyrosinase related protein-2 (TRP-2) tumour antigen on Lactococcus lactis
}

\author{
Jeevanathan Kalyanasundram', Suet Lin Chia², Adelene Ai-Lian Song ${ }^{1}$, Abdul Rahim Raha ${ }^{1,3}$, \\ Howard A. Young ${ }^{4}$ and Khatijah Yusoff ${ }^{2,3^{*}}$
}

\begin{abstract}
Background: The exploitation of the surface display system of food and commensal lactic acid bacteria (LAB) for bacterial, viral, or protozoan antigen delivery has received strong interest recently. The Generally Regarded as Safe (GRAS) status of the Lactococcus lactis coupled with a non-recombinant strategy of in-trans surface display, provide a safe platform for therapeutic drug and vaccine development. However, production of therapeutic proteins fused with cell-wall anchoring motifs is predominantly limited to prokaryotic expression systems. This presents a major disadvantage in the surface display system particularly when glycosylation has been recently identified to significantly enhance epitope presentation. In this study, the glycosylated murine Tyrosinase related protein-2 (TRP-2) with the ability to anchor onto the L. lactis cell wall was produced in suspension adapted Chinese Hamster Ovary (CHO-S) cells by expressing TRP-2 fused with cell wall anchoring LysM motif (CA) at the C-terminus.
\end{abstract}

Results: A total amount of $33 \mu \mathrm{g}$ of partially purified TRP-2-cA from $6.0 \mathrm{~g}$ in wet weight of CHO-S cells was purified by His-tag affinity chromatography. The purified TRP-2-cA protein was shown to be N-glycosylated and successfully anchored to the L. lactis cell wall.

Conclusions: Thus cell surface presentation of glycosylated mammalian antigens may now permit development of novel and inexpensive vaccine platforms.

Keywords: Surface display, Lactococcus lactis, Lysin motif, Tyrosinase related protein-2

\section{Background}

Surface display of engineered antigens on the Lactic acid bacteria (LAB) is currently being investigated as promising cellular vehicles for vaccine delivery [1-3]. This approach manipulates the natural cell surface molecular localisation of proteins that direct fundamental biological processes such as cell to inter-cell recognition, signal transduction, surface anchoring, colonisation and immunological interaction in living organisms [4]. Besides their GRAS (Generally Regarded as Safe) status compared to their attenuated pathogenic counterparts,

\footnotetext{
* Correspondence: kyusoff@upm.edu.my

${ }^{2}$ Department of Microbiology, Faculty of Biotechnology and Biomolecular Sciences, Universiti Putra Malaysia, 43400 UPM Serdang, Selangor Darul Ehsan, Malaysia

${ }^{3}$ Institute of Bioscience, Universiti Putra Malaysia, Serdang, Selangor Darul Ehsan, Malaysia

Full list of author information is available at the end of the article
}

the LAB, with probiotic and immunomodulatory properties have the ability to survive passage through both animals and humans for up to 5-7 days [5]. This has made $\mathrm{LAB}$ an excellent candidate for oral and intranasal vaccine development $[6,7]$. Therefore, LAB such as Lactococcus lactis can be genetically engineered to become an efficient recombinant cell factory for DNA delivery as well as production and presentation of antigens $[6,8]$. The presentation of antigens through surface display or secretion by $L$. lactis in numerous studies utilises the well understood and characterised surface binding protein domain such as transmembrane domains, lysin motif (LysM) and LPXTG motifs [9, 10].

Based on the findings described above, the LAB have the potential to be developed as a tumour antigen carrier for therapeutic or prophylactic cancer vaccines. Such cancer vaccines would be able to mount sustainable 
immune responses to eradicate primary tumours as well as prevent cancer relapses [11]. Since the early discovery of probiotic anti-tumour activity [12], the LAB have been primarily manipulated as prophylactic adjuvants for prevention of colorectal cancer [13] as well as breast and bladder cancers, albeit to a lesser extent. However, the exact mechanism of LAB anti-tumour activity has not been fully understood. It has been hypothesised that the competitive inhibition of $\mathrm{LAB}$ in the intestinal microflora may have resulted in disruption of metabolic equilibrium, digestion of potential carcinogens and promotion of a $\mathrm{T}$ helper 1 immune response through mucosal immunity $[14,15]$. Cancer antigen delivery by the $\mathrm{LAB}$, on the other hand, has not been widely explored and is only limited to two examples: 1) surface display of viral antigens from the human papillomavirus type- 16 (HPV-16) E7 antigen on L. lactis, Lactobacillus plantarum and Lactobacillus casei for cervical cancer treatment $[6,16]$ as well as 2) oncofetal antigen surface display by L. plantarum [17].

TRP-2 (Tyrosinase related protein-2) is an enzyme involved in melanin synthesis which undergoes $\mathrm{N}$ glycosylation and translocates into the melanosome in melanocytes. It has been reported to be a tumourassociated antigen present in both melanocytes and melanoma and as such, TRP-2 has been intensely studied as a viable therapeutic and prophylactic vaccine candidate for melanoma and glioblastoma $[18,19]$. The TRP-2 DNA vaccination for glioblastoma multiforme treatment has resulted in tumour regression and immunological targeting to increase chemotherapeutic drug sensitivity $[19,20]$. Therapeutic effects for melanoma by alphavirus (Venezuelan equine encephalitis virus, VEE) replicon [21], cytomegalovirus (CMV) [22], attenuated Salmonella typhimurium [23] and Listeria monocytogenes [24] carrying TRP-2 have also been reported. Surprisingly, despite good documentation of the role of LABs as adjuvants in mucosal immunogenicity $[25,26]$, these GRAS status bacteria have yet to be manipulated to express TRP-2 for both therapeutic and prophylactic settings. In addition, common autoimmunity side effects of hypopigmentation (vitiligo) resulting from TRP-2 (self-antigen) immunization have been observed to be dependent on the vaccine strategies [21, 27].

In this study, live L. lactis surface displaying posttranslationally modified TRP-2 in trans was developed with the intention of future use as a prophylactic and therapeutic cancer vaccine. To date, bacterial surface display systems for heterologous protein mainly utilize a recombinant surface display mechanism. However, these recombinant bacterial surface display systems are very much limited to non-glycosylated proteins [2, 3, 27, 28] since prokaryotic cells, which in general do not undergo post-translational modifications, are used as cell factories to produce the recombinant proteins fused to the surface display anchor domain. Thus, the recombinant bacterial surface display system may not be suitable if glycosylation is vital for the folding and function of target proteins [29]. The recent emergence of the in-trans surface display system $[9,30,31]$ provides an attractive platform for glycoprotein delivery. In the in-trans system, the protein of interest is fused with the target bacteria's surface anchoring motif (SAM), which is expressed and purified from a separate host cell before it is externally introduced to the bacterial cell wall. This strategy was utilised in this study by producing TRP-2-cA glycoprotein fused with lactococcal cell wall anchor domain in Chinese Hamster Ovary (CHO) cells before subsequent binding to $L$. lactis cell wall. To our knowledge, this is the first report of prokaryotes surface displaying a glycosylated mammalian protein.

\section{Methods}

Bacterial strains and culture conditions

Plasmid construction and cloning was carried out by utilizing the TOP $10 \mathrm{E}$. coli strain (Invitrogen, USA). The TOP 10 E. coli (Invitrogen, USA) was grown in LB broth by incubating at $37{ }^{\circ} \mathrm{C}$ for $12-16 \mathrm{~h}$ and shaken at $250 \mathrm{rpm}$. During positive transformation screening and maintenance, the TOP 10 E. coli (Invitrogen, USA) strain was grown in LB agar/broth supplemented with $100 \mu \mathrm{g} / \mathrm{ml}$ of ampicillin.

\section{Gene amplification and plasmids construction}

Both trp-2 ${ }_{1-472}$ epitope and $c A$ gene DNA template were codon optimized based on $\mathrm{CHO}$ cell codon frequency table (Codon Usage Database at http://www.kazusa.or.jp/ codon/cgi-bin/showcodon.cgi?species=10029) in reference to Mus musculus cell-line B16F10 TRP-2 [Accession no: EU554632.1] and L. lactis N-acetylmuramidase LysM motifs [Accession no: U17696.1]. However the native murine TRP-2 signal peptide, mtrp-2 $2_{1-23}$ was replaced with Chinese Hamster TRP-2, Cricetulus griseus, TRP-2, [Accession no: ERE88475.1] signal peptide, chTRP-2 ${ }_{1-23}$ to promote target protein production in $\mathrm{CHO}-\mathrm{S}$ cells. Additional linker sequence, 5'-GGCGGCTCCGGCG GCGGCTCCGGC-3' which corresponds to GGSGG GSG amino acid linker sequence was incorporated upstream to the cA sequence for gene synthesis. Six histidine repeats with an enterokinase cleavage site were also incorporated downstream of the aforementioned codon optimized, synthesized cA sequence.

The trp-2 1-472 epitope was amplified by trp-2 1-472 forward primer, 5'-ATATAAGCTTACCATGGGCCTG GTGCACTG-3' and reverse primer, 5'- ATATGGA TCCGTGGTGGTGGTGGTGGTGGCCGG -3' containing HindIII and BamHI restriction sites respectively. The 
$c A$ sequence was amplified by $c A$ forward primer 5'- G CGCGGATCCGGCGGCTCCGGCGGCGGCTC-3' and reverse primer 5'- ATATGCGGCCGCTCAGTGGTGG TGGTGGTGGTGGCCGGTCC -3' containing BamHI and NotI restriction sites. PCR reaction was carried out in $1 \times P f u$ reaction buffer containing $2 \mathrm{mM} \mathrm{MgSO} 4,0.2 \mathrm{mM}$ dNTP, 2 units of $P f u$ polymerase (Fermentas, USA), $0.5 \mu \mathrm{M}$ of forward and reverse primers and approximately 20 ng of DNA template. The thermal cycler temperature condition for a 20 cycle amplification was set at a $94{ }^{\circ} \mathrm{C} / 1 \mathrm{~min}, 62{ }^{\circ} \mathrm{C} / 1 \mathrm{~min}$ and $72{ }^{\circ} \mathrm{C} / 2.5 \mathrm{~min}$ with a final extension of $72{ }^{\circ} \mathrm{C} / 10 \mathrm{~min}$. Amplified trp-2 1-472 and $c A$ genes replicates were gel purified by using Wizard $^{\oplus}$ SV Gel and PCR Clean-Up System (Promega, USA). Both of the purified genes were then digested with $\mathrm{BamHI}$ at $37{ }^{\circ} \mathrm{C}$ for $3 \mathrm{~h}$ separately and ligated using T4 DNA Ligase (Fermentas, USA) at 1:1 gene ratio overnight at $4{ }^{\circ} \mathrm{C}$. The resulting DNA ligation mixture was used as a template to amplify $\operatorname{trp}-2_{1-472}-c A$ fusion gene by using trp-2 ${ }_{1-472}$ forward primer and $c A$ reverse primer under abovementioned PCR buffer conditions and thermal cycler temperature profile. The trp-2 $1-472^{-} c A$ fusion gene was gel purified as described previously. The pcDNA: $\operatorname{trp}-2_{1-472}-c A$ expression plasmid was constructed by ligating HindIII and NotI digested trp-2 $1-472^{-c A}$ fusion gene with HindIII and NotI digested pcDNA 3.1 His B (Invitrogen, USA). Ligated plasmid product was heat-transformed into E. coli TOP10 (Invitrogen, USA) cloning host.

\section{CHO-S cells maintenance}

Suspension-adapted FreeStyle ${ }^{\text {tw }}$ CHO-S cells (Invitrogen, USA) were routinely cultured in $30 \mathrm{ml}$ of $8 \mathrm{mM} \mathrm{L}$-glutamine supplemented FreeStyle ${ }^{\mathrm{rm}}$ CHO Expression Medium (Invitrogen, USA) at densities of 1.2-1.5 $\times$ $10^{6} \mathrm{cell} / \mathrm{ml}$ using disposable Erlenmeyer tissue culture flasks with vented caps (Thermo-Scientific, USA) and shaken at 125-135 rpm on orbital shakers placed in an incubator $\left(37{ }^{\circ} \mathrm{C}, 8 \% \mathrm{CO}_{2}\right)$. Cell viability and confluency were monitored by manual haemocytometer assisted cell counting which confirmed $98 \%$ nonaggregating cell viability during cell maintenance under the described condition.

\section{Plasmid DNA transfection into CHO-S cells}

Large scale plasmid extraction was carried out by using QIAGEN ${ }^{\circ}$ Plasmid Maxi Kit (QIAGEN, USA) in order to obtain a concentrated $(\sim 1 \mathrm{mg} / \mathrm{mL})$ target pcDNA: trp-2 ${ }_{1-472}-c A$ expression plasmid for transfection. Cells were sub-cultured with fresh medium at $0.5-0.6 \times 10^{6}$ cells/ml density a day prior to transfection, in order to obtain $1-1.5 \times 10^{6}$ cells $/ \mathrm{ml}$ confluency for transfection. The cell density was adjusted at $1 \times 10^{6}$ cells $/ \mathrm{ml}$ and the culture medium was replaced with fresh culture medium. A total $480 \mathrm{ml}$ culture was transfected by separately transfecting 16 replicates of $30 \mathrm{ml}$ cell culture in $125 \mathrm{ml}$ Erlenmeyer tissue culture flasks per constructed plasmids. The transfection was carried out by diluting $37.5 \mu \mathrm{l}$ of FreeStyle ${ }^{\mathrm{rt}} \mathrm{MAX}$ reagent (Invitrogen, USA) and $37.5 \mu \mathrm{g}$ plasmid DNA separately into $0.6 \mathrm{ml}$ of Opti-PRO ${ }^{\text {mat }}$ Serum Free Medium, SFM (Invitrogen, USA), and then the two solutions weremixed together. The resulting $1.2 \mathrm{ml}$ DNA-FreeStyle ${ }^{\mathrm{rm}} \mathrm{MAX}$ reagent mixture was incubated at room temperature for $10 \mathrm{~min}$. The mixture was then added drop wise into $1 \times 10^{6}$ cells $/ \mathrm{ml}$ cell suspension while gently swirling the flask and transfected cells were subsequently shaken at $135 \mathrm{rpm}$ for three days in a $\mathrm{CO}_{2}$ incubator at $37{ }^{\circ} \mathrm{C}$. Cells were harvested on the third day post-transfection for protein analysis by SDS-PAGE and Western Blot.

\section{Protein expression}

Approximately $0.3 \mathrm{~g}$ in wet weight of pcDNA: $\operatorname{trp}-2_{1-472^{-}} \mathrm{CA}$ transfected CHO-S cells and wild type CHO-S cells were resuspended in $1 \mathrm{~mL}$ of $20 \mathrm{mM}$ of sodium phosphate buffer, $\mathrm{pH} 7.5$ before being sonicated respectively in ice for 5 min with $50 \%$ pulse at maximum microctip sonication power. The cell lysate was clarified by centrifugation at 10 $000 \times \mathrm{g}$ for $10 \mathrm{~min}$ in $4{ }^{\circ} \mathrm{C}$. The supernatant was collected for both TRP-2 $24-472^{-}$CA fusion protein expression and its subsequent PNGase deglycosylation analysis via Western blot. The supernatant fraction of both transfected and wild type CHO-S cell were also used for the following TRP-2 subunit enzymatic assay.

\section{PNGase deglycosylation analysis}

The glycosylation status of TRP-2-cA fusion protein was determined by PNGase F (New England Biolabs, USA) deglycosylation assay. Briefly, $9 \mu \mathrm{l}$ of crude transfected CHO-S cell lysate $(\sim 2.0 \mathrm{mg} / \mathrm{ml})$ was mixed with $1 \mu \mathrm{l}$ of Glycoprotein Denaturing Buffer and boiled at $100{ }^{\circ} \mathrm{C}$ for 10 min. Then, $2 \mu \mathrm{l}$ of GlycoBuffer 2 and $10 \%$ NP40 were added to the denatured protein mixture together with $1 \mu \mathrm{l}$ of PNGase F enzyme. Appropriate amount of distilled water was added to obtain a final reaction volume of $25 \mu \mathrm{l}$. The reaction tubes were incubated at $37{ }^{\circ} \mathrm{C}$ for $2 \mathrm{~h}$ or $12 \mathrm{~h}$. The PNGase F deglycosylated crude TRP-2-cA fusion protein was analysed comparatively to the untreated control by Western Blot.

\section{Dopachrome tautomerization assay}

The melanogenic activity of the TRP-2 subunit within the TRP-2 $1-472$-cA fusion protein was tested through dopachrome tautomerization assay as described by Aroca et al., [32]. The substrate, L- dopachrome was prepared by mixing $160 \mu \mathrm{l}$ of $0.6 \mathrm{mM}$ of L-DOPA (Acros, USA) in $10 \mathrm{mM}$ sodium phosphate buffer, 
$\mathrm{pH} 6.0$ with $40 \mu \mathrm{l}$ of $4.8 \mathrm{mM}$ of sodium periodate (Acros, USA) which was also dissolved in the same buffer. The mixture was then diluted with $700 \mu \mathrm{l}$ of $10 \mathrm{mM}$ sodium phosphate buffer, $\mathrm{pH} 6.0$ yielding $0.1 \mathrm{mM}$ of Ldopachrome. A volume of $150 \mu \mathrm{l}$ of $0.1 \mathrm{mM} \mathrm{L}$-dopachrome was mixed with $50 \mu \mathrm{l}$ of transfected and wild type $\mathrm{CHO}-\mathrm{S}$ cell lysates respectively by triplicate wells of ELISA plates Nunc $^{\text {Tw }}$ MicroWell ${ }^{\text {Tw }} 96$ Well Microplates, Thermo Scientific, USA). The ELISA plate was then incubated at $30{ }^{\circ} \mathrm{C}$. Absorbance at $475 \mathrm{~nm}$ for both control and experiment reaction fractions were recorded for each 5 min interval for $20 \mathrm{~min}$.

\section{TRP-2 24-472-CA fusion protein purification}

The TRP- $244-472-\mathrm{CA}$ fusion protein was purified by using His-tag affinity chromatography. A total of $\sim 6.0 \mathrm{~g}$ in wet weight of CHO-S cells was suspended in $20 \mathrm{mM}$ phosphate buffer ( $\mathrm{pH} 7.5$ ) with $1 \mathrm{mM}$ PMSF. The cells suspension was divided into aliquots, and each aliquot was sonicated in ice for $5 \mathrm{~min}$ with $50 \%$ pulse at maximum microctip sonication power. Once sonicated, cells aliquots were pooled together and incubated in ice for an hour. The lysate was clarified by centrifugation at $20,000 \mathrm{x} g$ for $45 \mathrm{~min}$ and the resulting supernatant was filter sterilized. An appropriate amount of glycerol was added to the crude supernatant which ultimately resulted in $\sim 55 \mathrm{ml}$ of $20 \mathrm{mM}$ sodium phosphate buffer ( $\mathrm{pH} 7.5)$ with $5 \%$ glycerol (Buffer A) crude supernatant suspension.

Affinity chromatography was conducted by using $1 \mathrm{ml}$ HisTrap HP (GE Healthcare, USA) for Ni-NTA His tag purification at $\mathrm{pH}$ 7.5. The column was equilibrated with Buffer A before crude protein supernatant was applied to the column. The column was then washed using washing buffers; $20 \mathrm{mM}$ sodium phosphate buffer $\mathrm{pH} 7.5$ with $40 \mathrm{mM}$ of imidazole. The bound fraction was eluted with $20 \mathrm{mM}$ phosphate buffer $\mathrm{pH} 7.5$ with $250 \mathrm{mM}$ imidazole.

\section{Protein anchoring}

Protein anchoring to the L.lactis cell wall was conducted similar to the previously described in-trans surface display report [31]. Overnight L.lactis MG1363 culture grown in M17 broth [33] was subcultured into fresh $\mathrm{M} 17$ broth and grown until cell density $\mathrm{OD}_{600}$, reaches 0.5 or 0.6 . A volume of $100 \mu \mathrm{l}$ of cells from this suspension was harvested and resuspended in $100 \mu \mathrm{l}$ of $1 \times$ PBS. Approximately $30 \mu \mathrm{g}$ of target or control proteins and $300 \mu \mathrm{l}$ of M17 broth were added to the cell mixture. The cell-protein suspension was incubated at $30{ }^{\circ} \mathrm{C}$ with gentle shaking (70-90 rpm) for $2 \mathrm{~h}$. The cell-protein suspension was centrifuged and the cell pellet washed thrice with $1 \times$ PBS. The final washed cell pellet was resuspended in $200 \mu \mathrm{l}$ of $1 \times$ PBS for immunofluorescence microscopy analysis.

\section{Immunofluorescence microscopy analysis}

Cell wall anchoring status was determined by immunofluorescence microscopy based on fluorescence conjugated secondary antibody tagging. The Teflon Coated Immunofluorescence Slide (Polysciences, USA) $6 \mathrm{~mm}$ well was treated with $0.01 \%$ of Poly-L-Lysine solution (Sigma-Aldrich, USA) and washed thrice with $1 \times$ PBS. A volume of $50 \mu$ l L.lactis cells $\left(\sim 1 \times 10^{4}\right.$ cells $)$ was fixed on the slide well and incubated at room temperature for $30 \mathrm{~min}$ followed by $1 \times$ PBS washing. Cells were then coated with $4 \%$ paraformaldehyde and incubated at room temperature for 20 min before being washed three times with $1 \times$ PBS. The cells were blocked for $30 \mathrm{~min}$ with $3 \%$ BSA blocking solution and washed three times with $1 \times$ PBS. The fixed cells were incubated with AntiTRP2 Rabbit Polyclonal Antibody ab74073 (Abcam, USA) $(0.2 \mu \mathrm{g} / \mu \mathrm{l})$ in $1 \% \mathrm{BSA}$ (dissolved in $1 \times \mathrm{PBS})$, for $1 \mathrm{~h}$ at room temperature. The cells were then washed thrice with $1 \times$ PBS and incubated for $1 \mathrm{~h}$ at room temperature with Alexa Flour ${ }^{-} 488$ goat anti-rabbit Antibody (Molecular Probes ${ }^{\circ}$, USA) $(2 \mu \mathrm{g} / \mu \mathrm{l})$ prepared by 1:200 dilution in $1 \% \mathrm{BSA}$ (dissolved in $1 \times \mathrm{PBS}$ ). Cells were subsequently washed thrice with $1 \times$ PBS and subjected to 4;6-Diamidino-2-phenylindole, DAPI nucleic acid staining by incubating with $0.5 \mu \mathrm{g} / \mathrm{ml}$ DAPI, Dihydrochloride (Calbiochem, USA) for $30 \mathrm{~min}$. Post $1 \times$ PBS washing, cells were then coated with $10 \mu \mathrm{l}$ of Flourguard Antifade Mounting Solution (Sigma-Aldrich, USA).

The method was also repeated with cells which interacted with cA protein (obtained from Microbial Biotechnology Laboratory, Faculty of Biotechnology and Biomolecular Science, UPM) as positive control using Anti His.Tag ${ }^{\odot}$ Monoclonal (Novagen, USA) primary antibody and Goat Anti-Mouse Flourescein Conjugated (Calbiochem, USA) secondary antibody. For a negative control, cells were mixed with $30 \mu \mathrm{g}$ of wild type CHO-S cell crude intracellular protein in $1 \times$ PBS using the same method described earlier.

\section{Results}

\section{Plasmid construction}

In this study the mammalian expression plasmid harbouring a $\operatorname{tr} p_{1-472}-c A$ fusion gene, pcDNA: $\operatorname{tr} p_{1-472^{-}} c A$ was constructed. The heterologous gene was codon optimised, synthesized and cloned into pcDNA $3.1 \mathrm{His}$ B (Invitrogen, USA). The native murine TRP-2 signal peptide was replaced with the Chinese Hamster TRP-2 signal peptide as well as six histidine repeats and an enterokinase site was included at the 3'-end of the fusion gene. These modifications were carried out to aid target glycoprotein production in CHO-S cells and its subsequent purification. The resulting plasmid and heterologous fusion gene is described in Fig. 1. 


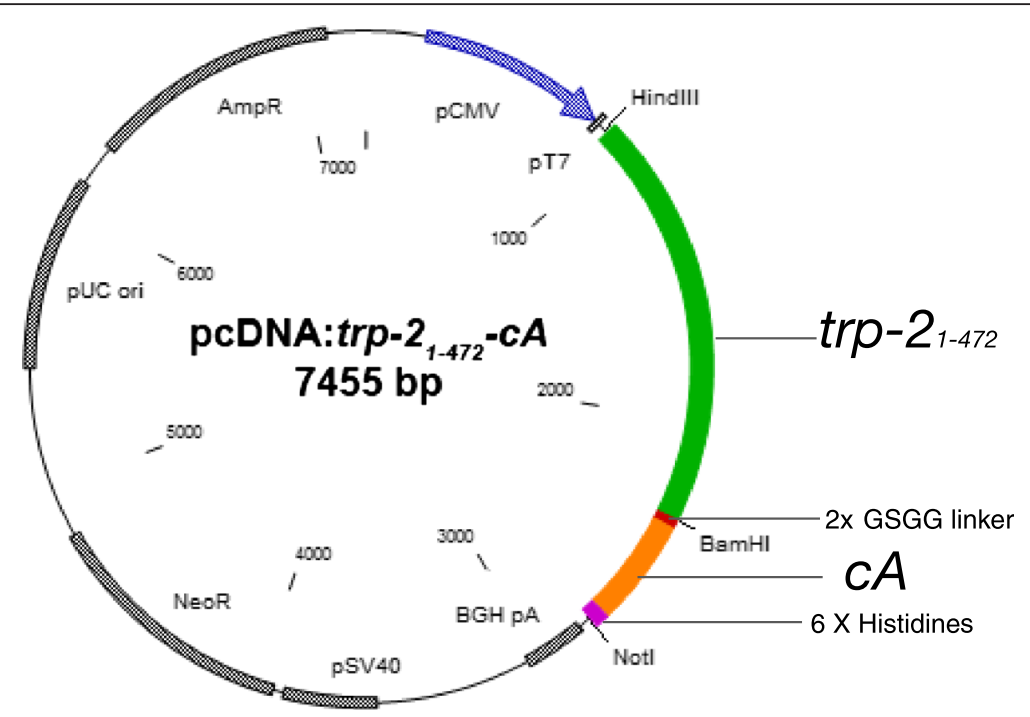

Fig. 1 Schematic diagram of pcDNA:trp-2 ${ }_{1-472}-\mathrm{CA}$

\section{Production \& purification of TRP-2 $24-472$-CA fusion glycoprotein}

The production of TRP- $2_{24-472}-\mathrm{cA}$ fusion glycoprotein by pcDNA: $\operatorname{tr} p_{1-472}-c A$ transfected CHO-S cells was analysed by SDS-PAGE and Western Blotting. Based on the Western Blot, the harvested crude protein supernatant showed TRP-2 $24-472-\mathrm{CA}$ as a specific band detected at $\sim 90 \mathrm{kDa}$ (Fig. 2). Since the predicted molecular weight with the absence of glycosylation for TRP- $24-472^{-c A}$ fusion protein was $\sim 74 \mathrm{kDa}$, the detection of a specific band with an excess of $\sim 16 \mathrm{kDa}$ was a preliminary indicator of potential glycan moieties present in the target protein. This was confirmed by PNGase F digestion which resulted in significant reduction in TRP-2 $24-472$-cA protein molecular weight from $\sim 90 \mathrm{kDa}$ to $\sim 70 \mathrm{kDa}$ after digestion (Fig. 2). Subsequently, the bio-functionality of the TRP-2 subunit in the target fusion protein was analysed through its ability to catalyse dopachrome tautomerization. The distinct decolorization of the L-dopachrome substrate (reduction in $\mathrm{A}_{475} \mathrm{~nm}$ ) was observed after 20 min incubation at $30{ }^{\circ} \mathrm{C}$ in the crude protein fraction containing TRP- $224-472^{-}$- $A$ fusion proteinsubstrate mixture, in contrast to wild-type CHO-S cell crude protein-substrate mixture (Table 1). This indicates that the TRP-2 subunit in fusion glycoprotein is enzymatically active.

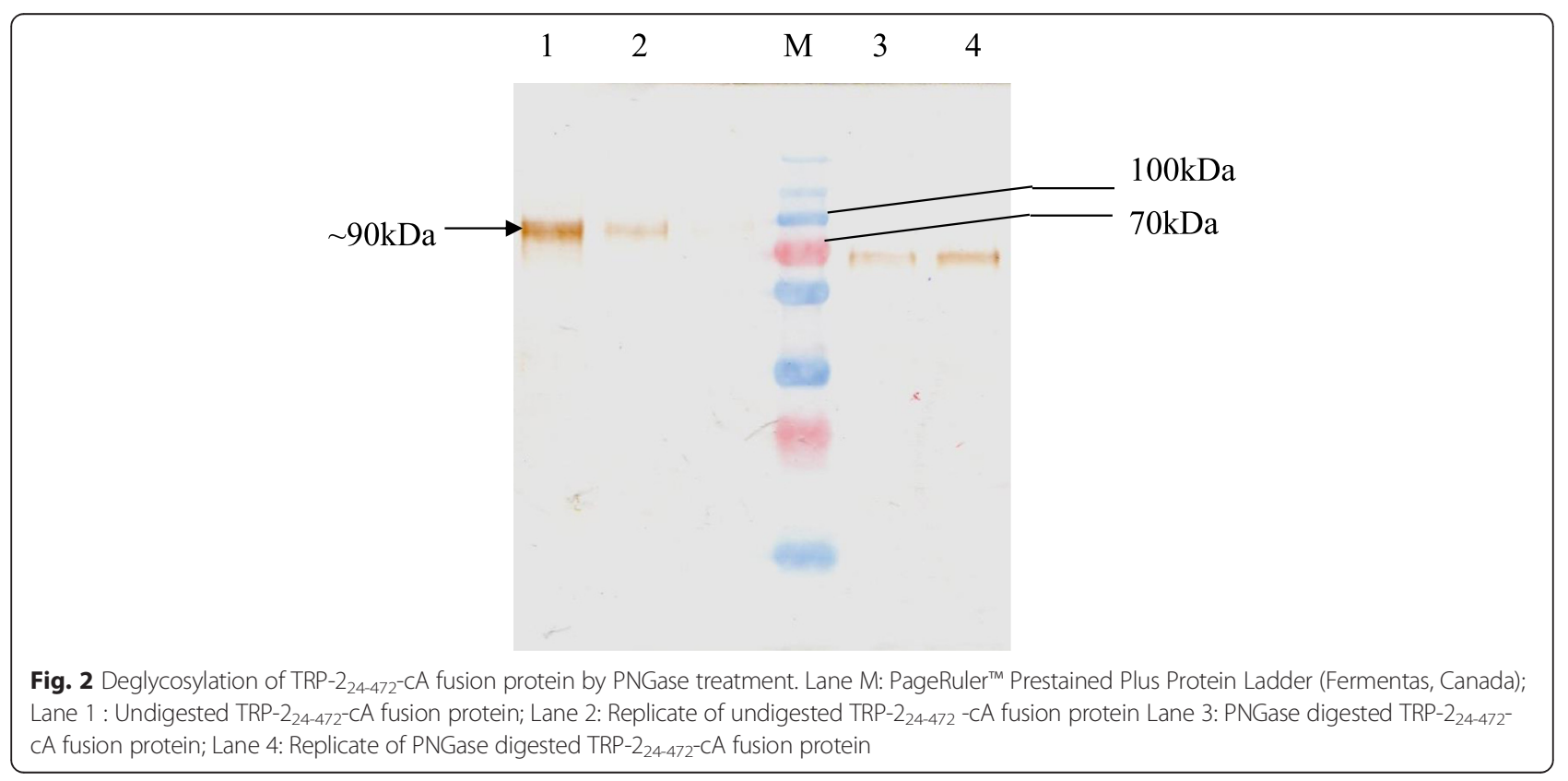


Table 1 OD475nm absorbance reading of L-dopachrome respectively mixed with wild-type CHO-S and transfected CHO-S crude protein

\begin{tabular}{|c|c|c|c|c|c|c|}
\hline \multirow{2}{*}{$\begin{array}{l}\text { Sample } \\
\text { Replicates }\end{array}$} & \multicolumn{3}{|c|}{ Wild type CHO-S crude protein extract } & \multicolumn{3}{|c|}{ pcDNA: $\operatorname{trp}-2_{1-472}-\mathrm{CA}$ transfected $\mathrm{CHO}-\mathrm{S}$ cell crude protein extract } \\
\hline & 1 & 2 & 3 & 1 & 2 & 3 \\
\hline $0 \mathrm{~min}$ & 0.203 & 0.205 & 0.202 & 0.205 & 0.208 & 0.206 \\
\hline 5 mins & 0.196 & 0.199 & 0.194 & 0.173 & 0.179 & 0.175 \\
\hline 10 mins & 0.184 & 0.188 & 0.180 & 0.140 & 0.147 & 0.143 \\
\hline 15 mins & 0.179 & 0.182 & 0.176 & 0.101 & 0.106 & 0.104 \\
\hline 20 mins & 0.170 & 0.173 & 0.168 & 0.093 & 0.098 & 0.095 \\
\hline
\end{tabular}

The crude supernatant harvested from $\sim 6.0 \mathrm{~g}$ of cells (wet weight) was subjected to His- tag affinity chromatography. Western blot analysis of the eluted fraction resulted in $\sim 90 \mathrm{kDa}$ target protein eluted at $250 \mathrm{mM}$ imidazole (Fig. 3).

\section{Immunofluorescence microscopy analysis}

Cell wall anchoring of glycosylated target protein, TRP-2 $24-472$ - $\mathrm{CA}$ was analysed to determine the biofunctionality of cA, the cell wall anchoring LysM motif. It was observed that the L. lactis MG1363 cells treated with TRP- $2_{24-472}-\mathrm{cA}$ and $\mathrm{cA}$ protein alone (positive control for immunofluorescence microscopy) respectively, emitted green fluorescence signals in contrast to those treated with the negative control (L.lactis treated with wild-type CHO-S crude protein in $1 \times$ PBS) (Fig. 4). This confirmed that the target glycoprotein, TRP-2 $24-472-\mathrm{CA}$, was anchored to the cell wall of $L$. lactis MG1363. In order to determine if the location of the target glycoprotein correlated with the presence of the $L$. lactis, DAPI staining was performed. As shown in Fig. 4, TRP-2 $24-472$-cA glycoprotein co-localized with $L$. lactis. Therefore, the target TRP-2 24-472-cA glycoprotein was expressed in-trans by L. lactis cells through the successful anchoring of the target to its cell wall.

\section{Discussion}

In this work, an in-trans surface display system was utilized to generate $L$. lactis surface displaying the mammalian glycoprotein TRP-2. A vaccine using nonrecombinant prokaryotes to deliver glycosylated eukaryotic proteins, is an attractive one, especially due to the low cost involved in generating sufficient quantities for the delivery system. Hitherto, bacterial in-trans and recombinant surface display of heterologous proteins were very much associated with non-glycosylated protein produced by prokaryotic cell factories. Such an approach is

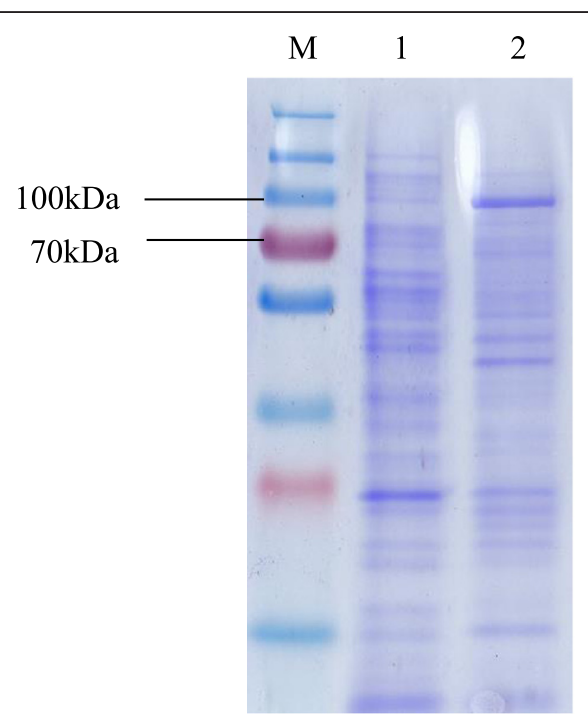

A

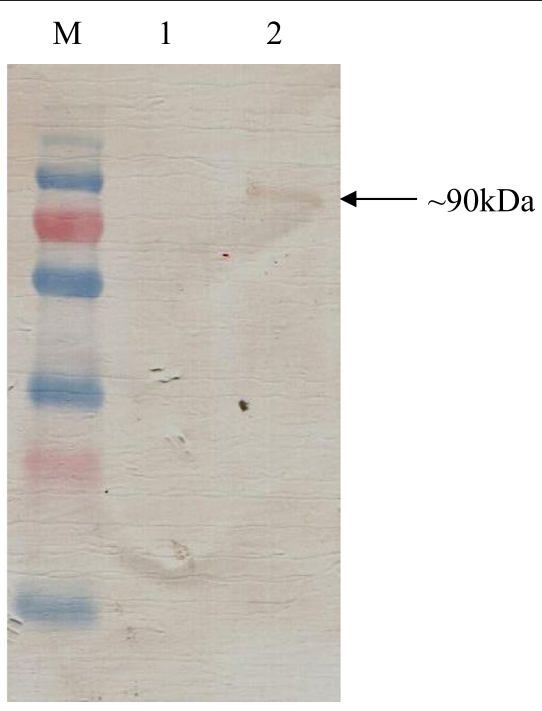

B

Fig. 3 Purification of TRP-224-472-CA by His-tag affinity chromatography. a SDS-PAGE profile; (b) Anti-His Western Blot profile. Lane M: PageRuler ${ }^{\text {TM }}$ Prestained Plus Protein Ladder (Fermentas, Canada); Lane 1: His-tag affinity chromatography unbound fraction; Lane 2: His-tag affinity chromatography $250 \mathrm{mM}$ imidazole eluted fraction 
(i)

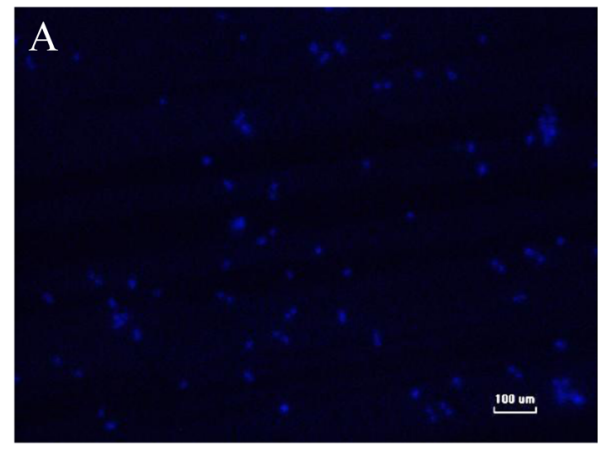

B
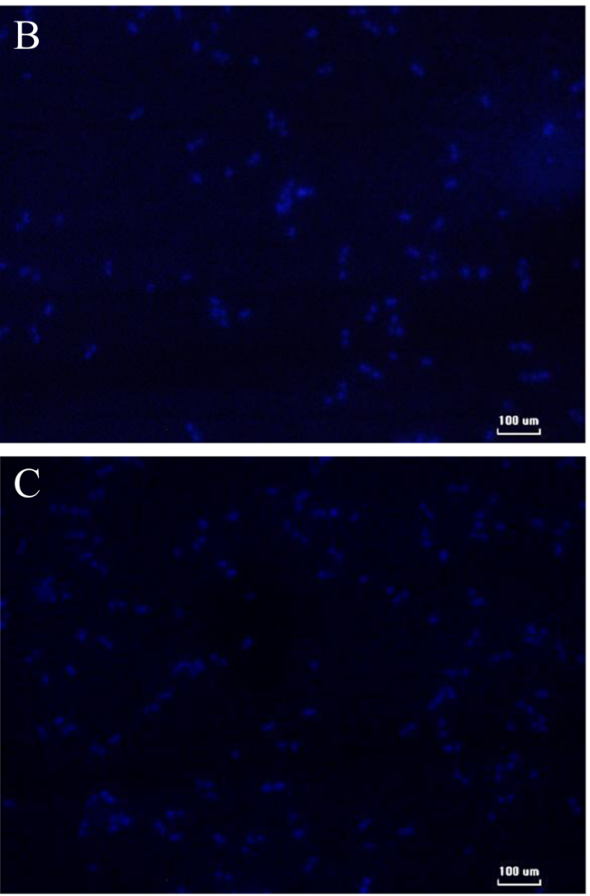

(ii)
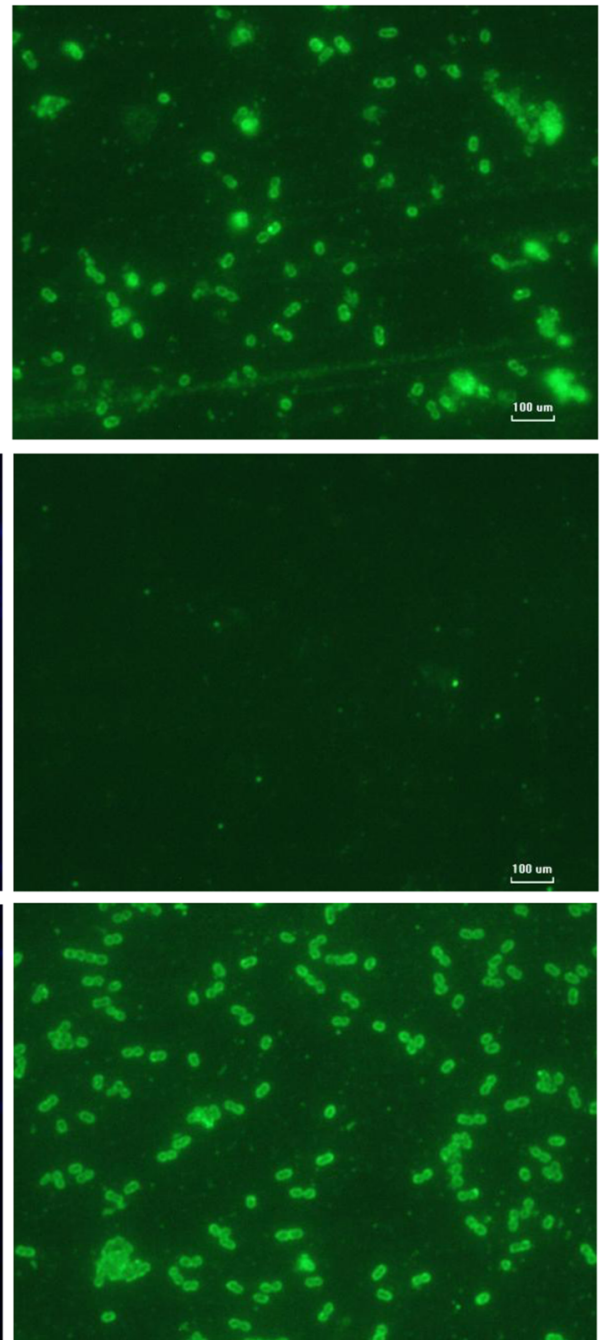

Fig. 4 Immunoflouroscence microscopy of L.lactis interacted with the TRP-224-472-CA glycoprotein. (i) DAPI nucleus staining for L. lactis cells (ii) FITC conjugated Secondary Antibody Staining. a L. lactis interacted with CA protein (expressed and purified E.coli), (b) L. lactis interacted with wild type CHO-S cells crude intracellular protein in 1 x PBS, (c) L. lactis interacted with TRP-2 $24-472$-CA glycoprotein

not suitable when the target protein requires posttranslational modifications for protein folding and biofunctionality.

L. lactis surface display applications have been predominantly involved in antigen or epitopes delivery for mucosal immunization through the oral route. This concept was first demonstrated in the streptococcal system by fusing the E7 protein of human papillomavirus type 16 with the C-terminal attachment motif of fibrillar M6 protein from Streptococcus pyogenes [34]. Since then, a similar strategy has been extensively manipulated in the lactococcal system by initially using sortase mediated cell wall anchoring motifs such as, LPXTG casein serine protein from L. lactis PrtP protein [35], S. pyogenes M6 protein [36] and Staphylococcus aureus protein A (SPA) anchor [37]. The non-covalent cell wall binding domain, cA (LysM-AcmA) domain, was compared with LPXTG motifs, i.e. PrtP using recombinant technology in surface displaying F18 Fimbrial Adhesin FedF, and was concluded to be more efficient [28].

Despite successful heterologous protein surface display for vaccine delivery by L.lactis through the nisin controlled gene expression system $\left(\mathrm{NICE}^{\varpi}\right)$, genetic modification of bacteria has been a safety concern. The GRAS status of L. lactis and many other LABs is insignificant as genetically modified microorganisms pose a risk of horizontal gene transfer, particularly antibiotic resistance gene transfer, in human and animal applications [10]. 
These challenges can be overcome by the in-trans surface display strategy which involves external cell wall binding of target protein -LysM (AcmA) fusion proteins produced from a host separate from the protein carrier. Such fusion proteins have been successfully produced in L. lactis [38], E.coli [9] and Pichia pastoris [39] before being purified and anchored to LAB peptidoglycan. The AcmA cell wall anchor also been used to bind recombinant proteins to killed L. lactis termed Gram-positive Enhancer Matrix (GEM) cells [40] as this system increases protein binding by removing hindering cell wall compartments and improves the biosafety of non-recombinant $L$. lactis vaccine.

Recently, N-glycosylation has been identified to significantly enhance epitope presentation of MHC class I molecules as demonstrated by using tyrosinase as a model antigen [41]. This is due to de-glycosylation by peptide $\mathrm{N}$-glycanase (PNGase) during the glycosylation process in the ER which allows deamidation for epitope presentation. Apart from that, proteolysis for epitope presentation was also discovered to slow down near the $\mathrm{N}$-glycan site thus resulting in the generation of native epitopes [42]. Previously however, the surface display strategy for glycosylated proteins has been restricted to yeast [43], but this system compromises the quality of the target glycoprotein, since yeast attach a different linkage of carbohydrate moieties (primarily mannose) to the core glycosyl unit and the system is highly susceptible to hyperglycosylation. Due to these differences, there is a preference for utilizing mammalian cells over yeast in generating therapeutic glycoproteins [44, 45]. The present study addresses these problems by utilizing the in-trans surface display system for glycoprotein delivery. In this study, TRP-2 glycoprotein fused with $L$. lactis $\mathrm{N}$-acetylmuramidase C-terminal LysM cell wall anchor, cA, was expressed in a mammalian cell (CHO-S cells) and subsequently anchored to the $L$. lactis cell wall. This study demonstrates that glycosylated antigens can be produced in a mammalian cell system and then can be anchored to a bacterial cell surface, by fusion with a cell wall anchoring motif such as cA.

Previously, most reported peptide based TRP-2 vaccines utilized highly antigenic short synthetic peptides (epitopes) i.e. TRP- $2_{180-188}[46,47]$, chiefly due to the difficulties in purifying the full length TRP-2 [32, 48]. Such an approach compromises the full length glycosylated TRP-2 immunogenic potential. Hitherto, high purity TRP-2 glycoprotein was successfully obtained from Sf9 insect cells but only upon the removal of the hydrophobic C-terminal transmembrane domain [48].

In this study, TRP-2 devoid of the transmembrane domain(TRP-2 24-472) was utilized to generate recombinant protein. In addition, in order to promote TRP-2 glycosylation and signal peptide recognition in the $\mathrm{CHO}-\mathrm{S}$ cell expression system, the murine TRP-2 signal peptide,
mTRP-2sp was substituted with Chinese Hamster TRP-2 maturation signal peptide, chTRP-2sp. Despite $91 \%$ amino acid sequence similarity between Chinese Hamster TRP-2 and murine TRP-2, the signal peptidase cleavage sequence varies considerably and the murine version was unable to promote proper localization in the CHO-S system (data not shown). Production of soluble TRP-2 $24-472-\mathrm{cA}$ by CHO-S cells enabled His-tag purification which resulted in the production of "partially purified" TRP-2 $24-472$-cA from recombinant CHO-S cells. Even though purity was poor, this method resulted in a protein fraction with enriched target protein.

The final phase of this study was to analyse the ability of TRP-2 $24-472$-cA glycoprotein to anchor onto the L. lactis cell wall. This assay was first demonstrated by Steen et al., [38] by interacting $15 \mu \mathrm{g}$ of cA protein expressed and purified from $L$. lactis NZ9700 with trichloroacetic acid-treated L. lactis. Since then, the in-trans approach has been applied to externally introduced target protein expressed and purified from E. coli $[9,30,31]$ to the L. lactis' cell wall. Similarly, the successful expression and purification of TRP-2 $24-$ $472^{-\mathrm{CA}}$ fusion glycoprotein from $\mathrm{CHO}-\mathrm{S}$ cells in this study generated a novel TRP-2 glycoprotein with $L$. lactis cell wall anchoring properties. The cA domain cell wall anchoring feature was confirmed by visualization of TRP-2 $24-472$-cA glycoprotein mixture with live $L$. lactis through immunofluorescence microscopy (Fig. 4). The functionality of prokaryotic ( $L$. lactis) cell wall anchoring domain, cA expressed and purified from eukaryotes has been previously demonstrated [39]. The aforementioned study successfully docked yeast produced cA, which was mutated to eliminate $\mathrm{N}$-glycosylation sites thought to possibly hinder docking, onto the cell surface of Lactobacillus casei NRRL B-441 [39]. Despite none of the predicted $\mathrm{N}$-glycosylation sites present in the cA domain were eliminated in this study, the anchoring motif was shown to be fully functional and capable of anchoring glycosylated TRP-2 onto the L. lactis' cell wall.

While the concept of surface displaying glycosylated eukaryotic proteins on prokaryotic bacteria using the above approach was proven successful, the major drawback has been the initial low expression of the target fusion protein produced by the transient $\mathrm{CHO}-\mathrm{S}$ expression system. This restriction has accounted for difficulties in accumulating sufficient amount of the pure target proteins, limiting the study to the characterization of the glycosylation of the TRP-2 $24-472^{-c A}$ fusion protein and immunogenicity analysis using in vivo models. Optimization of the current transient expression system or development of a stable cell line expressing the TRP- $2_{24-472}$-cA fusion protein will have to be carried out before the system can be fully utilized. 


\section{Conclusion}

In summary, this study represents a novel method of displaying eukaryotic proteins on bacterial carriers such as L. lactis when post-translational glycosylation is crucial for functionality. The system developed in this study, i.e. L. lactis surface displaying TRP-2, is anticipated to be able to function as a cancer vaccine which will be investigated in future studies once sufficient target protein production is achieved. The vaccine which could be administered orally or intranasally, would likely to induce an antigen specific immune response against glioma and melanoma cells, triggering immune effectors including antigen specific CD8+ cells and antibodies as has been detected in other studies utilizing LAB as antigen carriers.

\section{Abbreviations \\ CA: C-terminal lysin motifs of L. lactis N-acetylmuramidase; CHO-S: suspension adapted Chinese Hamster Ovary cells; DAPI: 4',6-Diamidino-2-phenylindole; FITC: fluorescein isothiocyanate; GRAS: generally regarded as safe; LAB: lactic acid bacteria; L-DOPA: L-3,4-dihydroxyphenylalanine; LysM: Iysin motifs; PBS: phosphate buffer saline; PMSF: Phenylmethylsulfonyl fluoride; SAM: surface anchoring motifs; TRP-2: tyrosinase related protein 2.}

\section{Competing interests}

The authors declare that they have no competing interests.

\section{Authors' contributions}

JK designed the research, conducted the reported experiments, data analysis and wrote the manuscript. SLC assisted the scientific experiments as well as writing process. AALS contributed to the manuscript editing and guiding its submission. ARR proposed the research concept and providing necessary tools for experiments. HAY introduced the utilized tumour antigen and the writing of the manuscript. KYsecured the funding and workstation for the project. All authors read and approved the final manuscript.

\section{Acknowledgements}

The research was funded by Malaysian Ministry of Science, Technology and Innovation (Grant Number: 02-01-04-SF1273). We would like to thank Dr. Andrew Hurwitz of US National Cancer Institute for providing TRP-2 cDNA. A portion of this work was supported by funding to H.A.Y. by the intramural research program of the U. S. National Cancer Institute.

\section{Author details \\ ${ }^{1}$ Department of Cell and Molecular Biology, Faculty of Biotechnology and Biomolecular Sciences, Universiti Putra Malaysia, Serdang, Selangor Darul Ehsan, Malaysia. ${ }^{2}$ Department of Microbiology, Faculty of Biotechnology and Biomolecular Sciences, Universiti Putra Malaysia, 43400 UPM Serdang, Selangor Darul Ehsan, Malaysia. ${ }^{3}$ Institute of Bioscience, Universiti Putra Malaysia, Serdang, Selangor Darul Ehsan, Malaysia. ${ }^{4}$ Cancer and Inflammation Program, Center for Cancer Research, National Cancer Institute, Frederick, MD, USA.}

Received: 16 July 2015 Accepted: 22 December 2015

Published online: 29 December 2015

\section{References}

1. Ramasamy R, Yasawardena S, Zomer A, Venema G, Kok J, Leenhouts K. Immunogenicity of a malaria parasite antigen displayed by Lactococcus lactis in oral immunisations. Vaccine. 2006;18(24):3900-8.

2. Lim SH, Jahanshiri F, Rahim RA, Sekawi Z, Yusoff K. Surface display of respiratory syncytial virus glycoproteins in Lactococcus lactis NZ9000. Lett Appl Microbiol. 2010;51(6):658-64.
3. Cortes-Perez NG, Azevedo V, Alcocer-González JM, Rodriguez-Padilla C, Tamez-Guerra RS, Corthier G, et al. Cell-surface display of E7 antigen from human papillomavirus type-16 in Lactococcus lactis and in Lactobacillus plantarum using a new cell-wall anchor from lactobacilli. J Drug Target. 2005;13(2):89-98.

4. Westerlund B, Korhonen TK. Bacterial proteins binding to the mammalian extracellular matrix. Mol Microbiol. 1993;9:687-94.

5. Perdigón G, Fuller R, Raya R. Lactic Acid Bacteria and their Effect on the Immune System. Curr Issues Intest Microbiol. 2001;2(1):27-42.

6. Pontes DS, de Azevedo MSP, Chatel JM, Langella P, Azevedo V, Miyoshi A. Lactococcus lactis as live vector: Heterologous protein production and DNA delivery systems. Protein Expr Purif. 2011;79(2):165-75.

7. Li X, Xing Y, Guo L, Lv X, Song H, Xi T. Oral immunization with recombinant Lactococcus lactis delivering a multi-epitope antigen CTB-UE attenuates Helicobacter pylori infection in mice. Pathog Dis. 2014;72(1):78-86. doi:10.1111/2049-632X.12173.

8. Morello E, Bermudez-Humaran LG, Llull D, Sole V, Miraglio N, Langella P, et al. Lactococcus lactis, an Efficient Cell Factory for Recombination Protein Production and Secretion. J Mol Microbiol Biotechnol. 2008;14:48-58.

9. Raha AR, Varma NRS, Yusoff K, Ross E, Foo HL. Cell surface display system for Lactococcus lactis: a novel development for oral vaccine. Appl Microbiol Biotechnol. 2005;68:75-81.

10. Bahey-El-Din M, Gahan CG, Griffin BT. Lactococcus lactis as a Cell Factory for Delivery of Therapeutic Proteins. Current Gene Ther. 2010;10:34-4.

11. Pejawar-Gaddy S, Finn OJ. Cancer vaccines: Accomplisments and Challenges. Critical Reviews in Oncology. Hematology. 2008;93-102.

12. Kelkar SM, Shenoy MS, Kaklij GS. Antitumour activity of lactic acid bacteria on a solid fibrosarcoma, sarcoma-180 and Ehrlich ascites carcinoma. Cancer Lett. 1988:42:73-7.

13. Satonaka K, Ohashi K, Nohmi T, Yamamoto T, Abe S, Uchida K, et al. Prophylactic effect of Enterococcus faecalis FK-23 preparation on experimental candidiasis in mice. Microbiol Immunol. 1996;40:217-22.

14. Rafter J. Lactic acid bacteria and cancer: mechanistic perspective. Br J Nutr Suppl. 2002;Suppl 1:S89-94.

15. Matsuzaki T, Chin J. Modulating immune responses with probiotic bacteria. Immunol Cell Biol. 2000;78(1):67-73.

16. Ribelles $P$, Benbouziane $B$, Langella $P$, Suárez JE, Bermúdez-Humarán LG. Protection against human papillomavirus type 16-induced tumors in mice using non-genetically modified lactic acid bacteria displaying E7 antigen at its surface. Appl Microbiol Biotechnol. 2013;97(3):1395.

17. Fredriksen L, Mathiesen G, Sioud M, Vincent GHE. Cell Wall Anchoring of the 37-Kilodalton Oncofetal Antigen by Lactobacillus plantarum for Mucosal Cancer Vaccine Delivery. Appl Environ Microbiol. 2010;76(21):7359-62.

18. Yamano T, Kaneda Y, Sharon H, Hiramatsu HS, Hoon DS. Enhancement of Immunity by a DNA melanoma vaccine against TRP2 with CCL21 as an adjuvant. Mol Ther. 2005;13:194-202.

19. InSug O, Blaszczyk-Thurin M, Shen C, Ertl HC. A DNA vaccine expressing tyrosinase-related protein 2 induces T-cell-mediated protection against mouse glioblastoma. Cancer Gene Ther. 2003;10:678-88.

20. Liu G, Akasaki Y, Khong HT, Wheeler CJ, Das A, Black KL, et al. Cytotoxic T cell targeting of TRP-2 sensitizes human malignant glioma to chemotherapy. Oncogene. 2005;24:5226-34.

21. Avogadri F, Merghoub T, Maughan MF, Hirschhorn-Cymerman D, Morris J, Ritter E, et al. Alphavirus Replicon Particles Expressing TRP-2 Provide Potent Therapeutic Effect on Melanoma through Activation of Humoral and Cellular Immunity. PLoS ONE. 2010;5(9):e12670. doi:10.1371/journal.pone. 0012670.

22. Xu G, Smith T, Grey F, Hill AB. Cytomegalovirus-based cancer vaccines expressing TRP-2 induced rejection of melanoma in mice. Biochem Biophys Res Commun. 2013:437(2):287-91.

23. Zhu X, Cai J, Huang J, Jiang X, Ren D. The treatment and prevention of mouse melanoma with an oral DNA vaccine carried by attenuated Salmonella typhimurium. J Immunother. 2010;33(5):453-60.

24. Bruhn KW, Craft N, Nguyen BD, Yip J, Miller JF. Characterization of anti-self CD8 T-cell responses stimulated by recombinant Listeria monocytogenes expressing the melanoma antigen TRP-2. Vaccine. 2005;23(33):4263-72.

25. Kajikawa A, Masuda K, Mitsunori K, Shizunobu I. Adjuvant Effects for Oral Immunization Provided by Recombinant Lactobacillus casei Secreting Biologically Active Murine Interleukin-1. Clin Vaccine Immunol. 2010;17:43-8.

26. Mercenier A, Müller-Alouf H, Grangette C. Lactic acid bacteria as live vaccines. Curr Issues Mol Biol. 2000;2:17-25. 
27. Steitz J, Brück J, Steinbrink K, Enk A, Knop J, Tüting T. Genetic immunization of mice with human tyrosinase-related protein 2: implications for the immunotherapy of melanoma. Int J Cancer. 2000;86(1):89-94.

28. Lindholm A, Smeds A, Palva A. Receptor binding domain of Escherichia coli F18 fimbrial adhesin FedF can be both efficiently secreted and surface displayed in a functional form in Lactococcus lactis. Appl Environ Microbiol. 2004;70(4):2061-71.

29. Kwaks TH, Otte AP. Employing epigenetics to augment the expression of therapeutic proteins in mammalian cells. Trends Biotechnol. 2006;3:137-42.

30. Varma NRS, Toosa H, Foo HL, Alitheen NBM, Nor Shamsudin M, Arbab AS, et al. Display of the viral epitopes on Lactococcus lactis: a model for food grade vaccine against EV71. Biotechnol Res Int. 2013;2013:431315.

31. Moeini H, Rahim RA, Omar AR, Shafee N, Yusoff K. Lactobacillus acidophilus as a live vehicle for oral immunization against chicken anemia virus. Appl Microbiol Biotechnol. 2011:90:77-88.

32. Aroca P, Garcia-Borron JC, Solano F, Lozano JA. Regulation of mammalian melanogenesis. I: Partial purification and characterization of a dopachrome converting factor: dopachrome tautomerase. Biochim Biophys Acta. 1990;1035(3):266-75.

33. Terzaghi BE, Sandine WE. Improved medium for lactic streptococci and their bacteriophages. Appl Microbiol. 1975;29:807-13.

34. Pozzi G, Contorni M, Oggioni MR, Manganelli R, Tommasino M, Cavalieri F, et al. Delivery and expression of a heterologous antigen on the surface of streptococci. Infect Immun. 1992;60(5):1902-7.

35. Robinson K, Chamberlain LM, Schofield KM, Wells JM, Le Page RW. Oral vaccination of mice against tetanus with recombinant Lactococcus lactis. Nat Biotechnol. 1997;15(7):653-7.

36. Piard JC, Hautefort I, Fischetti VA, Ehrlich SD, Fons M, Gruss A. Cell wall anchoring of the Streptococcus pyogenes M6 protein in various lactic acid bacteria. J Bacteriol. 1997;179(9):3068-72.

37. Steidler L, Robinson K, Chamberlain L, KM S e, Remaut E, Le Page RW, et al. Mucosal delivery of murine interleukin-2 (IL-2) and IL-6 by recombinant strains of Lactococcus lactis coexpressing antigen and cytokine. Infect Immun. 1998;66(7):3183-9.

38. Steen A, Buist G, Leenhouts KJ, El Khattabi M, Grijpstra F, Zomer AL, et al. Cell wall attachment of a widely distributed peptidoglycan binding domain is hindered by cell wall constituents. J Biol Chem. 2003;278:23874-81.

39. Tarahomjoo S, Katakura Y, Satoh E, Shioya S. Expression of C-terminal repeat region of peptidoglycan hydrolase of Lactococcus lactis IL1403 in methylotrophic yeast Pichia pastoris. J Biosci Bioeng. 2008;105(2):134-9.

40. Bosma T, Kanninga R, Neef J, Audouy SA, van Roosmalen ML, Steen A, et al. Novel surface display system for proteins on non-genetically modified gram-positive bacteria. Appl Environ Microbiol. 2006;72(1):880-9.

41. Ostankovitch M, Altrich-Vanlith M, Robila V, Engelhard VH. N-glycosylation enhances presentation of a MHC class I-restricted epitope from tyrosinase. J Immunol. 2009;182:4830-5.

42. Boder ET, Wittrup KD. Yeast surface display for screening combinatorial polypeptide libraries. Nat Biotechnol. 1997;15:553-7.

43. Romanos M. Advances in the use of Pichia pastoris for high-level gene expression. Curr Opin Biotechnol. 1995:6:527-33.

44. Stratton-Thomas JR, Min HY, Kaufman SE, Chiu CY, Mullenbach GT, Rosenberg S. Yeast expression and phagemid display of the human urokinase plasminogen activator epidermal growth factor-like domain. Protein Eng. 1995;8(5):463-70.

45. Davila E, Kennedy R, Celis E. Generation of antitumor immunity by cytotoxic T lymphocyte epitope peptide vaccination, CpG-oligodeoxynucleotide adjuvant, and CTLA-4 blockade. Cancer Res. 2003;63(12):3281-8.

46. Miconnet I, Coste I, Beermann F, Haeuw JF, Cerottini JC, Bonnefoy JY, et al. Cancer vaccine design: a novel bacterial adjuvant for peptide-specific CTL induction. J Immunol. 2001;166(7):4612-9.

47. Tsukamoto K, Jackson IJ, Urabe K, Montague PM, Hearing VJ. A second tyrosinase-related protein, TRP-2, is a melanogenic enzyme termed DOPAchrome tautomerase. EMBO J. 1992;11(2):519-26.

48. Vavricka CJ, Ray KW, Christensen BM, Li J. Purification and N-glycosylation analysis of melanoma antigen dopachrome tautomerase. Protein J. 2010;29(3):204-1.

\section{Submit your next manuscript to BioMed Central and we will help you at every step:}

- We accept pre-submission inquiries

- Our selector tool helps you to find the most relevant journal

- We provide round the clock customer support

- Convenient online submission

- Thorough peer review

- Inclusion in PubMed and all major indexing services

- Maximum visibility for your research

Submit your manuscript at www.biomedcentral.com/submit 